\title{
Aripiprazole Improved Obsessive Compulsive Symptoms in Asperger's Disorder
}

\author{
Gonca Celik, Aysegul Yolga Tahiroglu, Sunay Firat, Ayşe Avci \\ Department of Child Adolescent Psychiatry, Çukurova University, Adana, Turkey
}

\begin{abstract}
There are many comorbid disorders associated with autism spectrum disorders in child and adolescent population. Although obsessive compulsive disorder and autism spectrum disorders (ASD) comorbidity has common in clinical practice, there are few reports about psychopharmacological treatment for obsessive compulsive symptoms in children with ASD in the literacy. We report a successful treatment case with aripiprazole in Asperger's Disorder with obsessive compulsive symptoms. The Yale Brown Obsessive Compulsive Scale was performed to assess symptom variety. This case report supports the effectiveness of aripiprazole in treatment of obsessive compulsive symptoms in Asperger's Disorder or ASDs. Aripiprazole may be beneficial to obsessive compulsive disorder comorbid autism spectrum disorders in child and adolescent age group.
\end{abstract}

KEY WORDS: Asperger; Aripiprazole; Obsessive compulsive disorder.

\section{INTRODUCTION}

Pervasive developmental disorders also called autism spectrum disorders (ASDs) including autistic disorder, Asperger's disorder and pervasive developmental disorder not otherwise specified are neurodevelopmental disorders of early childhood onset characterized by impairments in social interaction, communication problems, unusual preoccupations, and repetitive behavior. ${ }^{1)}$

Repetitive routines and rituals are frequent in autism and many of these behaviors are identical to those seen in obsessive compulsive disorder (OCD). ${ }^{2)}$ The most important mechanism is disruption in serotonergic pathway in OCD and autism. ${ }^{3)}$ Also 5-HT function and 5-HT1D sensitivity may play a role in mediating one specific behavioral domain within autism repetitive behaviors. ${ }^{4)}$

Restricted repetitive behaviors are a heterogeneous group of behaviors, ranging from repetitive movements of the body to more cognitively mediated symptoms such as intense interests or preoccupations. ${ }^{1)}$ Consequently, the repetitive behavior and obsessive preoccupation may overlap in same clinical spectrum. Descriptive data sug-

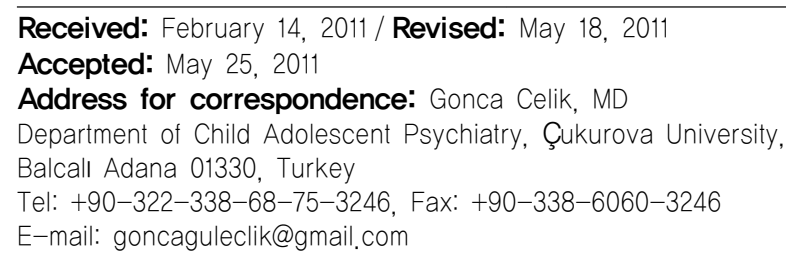

gests that different age-related patterns are associated with the various types of repetitive behaviors. ${ }^{5)}$

Although OCD and ASD comorbidity has common in clinical practice, there are few reports about psychopharmacological treatment for obsessive compulsive symptoms in children with ASD in the literacy. ${ }^{6-8)}$ The purpose of this study is to present a successful treatment case with aripiprazole in Asperger's disorder with obsessive compulsive symptoms.

\section{CASE}

A boy at the age of 15 had been treated and followed up in our outpatient clinic with diagnosis of Asperger's syndrome since the age of 5 . He had not been given any pharmacotherapy in prior time. His developmental milestones are within normal ranges. For example; he began to walk at 14 months and he had few words at 13 months. He had poor eye contact and inappropriate interaction and avoidance in peer relations at an earlier age. His family firstly noticed his symptoms that he had not responded his name at 13 months.

He had obsessive thoughts such as feeling guilty about his homosexual thoughts and masturbating acts, preoccupation about stock farming, and compulsions such as counting bath stones since one year. Additionally, he had excessively interested in theory of evolution of mankind. He had poor insight about his obsessions but his parents 
felt very anxious about his preoccupations. These obsessions occupied much of his time in a day and he couldn't finish his homework.

Wechsler Intelligence Scale for Children-Revised (WISC-R) intelligence quotient (IQ) test was applied; verbal IQ point was determined as 93; performance IQ point as 96; and total IQ point as 94. The results of neurologic evaluations including electroencephalogram and magnetic resonance imaging were normal. His blood biochemical parameters were found within the normal range. Aripiprazole $5 \mathrm{mg} /$ day was started. After two weeks the dose was titrated up to $10 \mathrm{mg}$ /day because of partially improvement seen in his symptoms. No side effect was observed. Baseline Yale Brown Obsession Compulsion Scale (YBOCS) score was determined as 31 (compulsion score: 14, obsession score: 17). Three weeks after the treatment, significant improvement was observed in counting and preoccupation but feeling guilty about masturbation and homosexual thoughts remained. His obsessive preoccupations in addition to his speech and social reciprocity were improved according to his teacher's and mother's reports. For example, he began to call and go out with his friends out of school regularly and his eye-contact in the school and at home mildly improved. In the psychiatric interviews, he has more relaxed, not anxious any more and gained sense of humors, especially about himself.

After three weeks of aripiprazole treatment, YBOCS score was determined as 13 (compulsion score: 7, obsession score: 6); and improvement was increased by $50 \%$ according to CGI.

\section{DISCUSSION}

Comorbid conditions such as schizophrenia, bipolar disorder and attention-deficit hyperactivity disorder have been reported in Asperger's Syndrome. ${ }^{9,10)}$ Furthermore, symptoms such as obsession may predict the prodromal phases of other psychiatric disorders. Patients with OCD were given aripiprazole $10-30 \mathrm{mg}$ in an open-label fashion for 8 weeks. Seven out of 13 patients were evaluated. The mean total change in YBOCS from baseline was 6.3 points (23.9 to 17.6$)$. Three patients $(42.9 \%)$ had met the criterion for response, based on a greater than or equal to $\geq 30 \%$ reduction in YBOCS score from baseline. ${ }^{11)}$ Adult case series about aripiprazole usage in bipolar disorder and comorbid OCD have been reported successful reduction of mean YBOCS score. ${ }^{12)}$

There are very limited data about treatment of obsessive compulsive symptoms in the ASD patients. In a case of
Asperger's disorder with obsessive thoughts, manic switch was reported during selective serotonin reuptake inhibitor (SSRI) treatment. ${ }^{7)}$ King et al. ${ }^{8)}$ suggest that citalopram has lack of efficacy in treatment of obsessive compulsive symptoms and repetitive behaviors as measured on the YBOCS. Sexual obsessional preoccupations may be explained with his normal adolescent developmental stage, but the symptoms were thought to be persisting.

In addition, contrary findings were seen about SSRI use in ASDs population. ${ }^{13)}$ For this reason, we did not consider SSRI use at first step in treatment, although SSRIs are generally chosen in treatment of OCD. Aripiprazole was chosen to start treatment because we thought that it could be effective in treating symptoms of both Asperger's disorder and OCD. Aripiprazole is a partial agonist at the D2 and 5-HT1A receptors and an antagonist at the 5-HT 2A receptors. Unlike other atypical antipsychotics which have varying levels of D2 receptor antagonism, aripiprazole is a partial agonist at the D2 and 5-HT1A receptors which may be account for anti obsessional mechanism. ${ }^{14)}$

In summary, in three weeks his obsessive thoughts were been improved remarkably and counting compulsions were decreased. There are some similar evidences corroborating our findings; aripiprazole has been found useful in the behavioral problems of ASD cases. ${ }^{15)}$

In conclusion, this report suggests aripiprazole treatment in ASD with obsessive compulsive symptoms in adolescent patient group.

\section{REFERENCES}

1. American Psychiatric Association. Diagnostic and Statistical Manual of Mental Disorders, Text Revision. 4th ed. Washington, DC: American Psychiatric Association; 2000.

2. Kobayashi R, Murata T. Behavioral characteristics of 187 young adults with autism. Psychiatry Clin Neurosci 1998; 52:383-390.

3. Apter A, Brown S, Korn ML, Van Praag HM. Psychiatric disorders of childhood: The role of serotonin. In: Brown $S$, Van Praag HM, editors. The role of serotonin in psychiatric disorders: Clinical and experimental psychiatry monograph. Philadelphia: Brunner/Mazel; 1991. p.215-231.

4. Hollander E, Novotny S, Allen A, Aronowitz B, Cartwright $\mathrm{C}$, De Caria C. The relationship between repetitive behaviors and growth hormone response to sumatriptan challenge in adult autistic disorder. Neuropsychopharmacology 2000;22: 163-167.

5. Lam KS, Aman MG. The repetitive behavior scale revised: independent validation in individuals with autism spectrum disorders. J Autism Dev Disord 2007;37:855-866.

6. Damore J, Stine J, Brody L. Medication induced hypomania in Asperger's disorder. J Am Acad Child Adolesc Psychiatry 1998;37:248-249.

7. Storch DD. Medication induced hypomania in Asperger 
disorder. J Am Acad Child Adolesc Psychiatry 1999;38: 110-111.

8. King BH, Hollander E, Sikich L, Mccracken JT, Scahill L, Bregman JD, et al. Lack of efficacy of citalopram in children with autism spectrum disorders and high levels of repetitive behavior: citalopram ineffective in children with autism. Arch Gen Psychiatry 2009;66:583-590.

9. Ghaziuddin M, Widmer-Mikhail E, Ghaziuddin N. Comorbidity of Asperger's syndrome: a preliminary report. J Intellect Disabil Res 1998;42:279-283.

10. Gutkovich ZA, Carlson GA, Carlson HE, Coffey B, Wieland N. Asperger's disorder and co-morbid bipolar disorder: diagnostic and treatment challenges. J Child Adolesc Psychopharmacol 2007;17:247-255.

11. Conner KM, Payne VM, Gadde KM, Zhang W, Davidson JR. The use of aripiprazole in obsessive compulsive disorder: preliminary observations in 8 patients. J Clin Psychiatry 2005;66:49-51.
12. Uguz F. Succesfull treatment of comorbid obsessive compulsive disorder with aripiprazole in three patients with bipolar disorder. Gen Hosp Psychiatry 2010;32:556-558.

13. Williams K, Wheeler DM, Silove N, Hazell P. Selective serotonin reuptake inhibitors (SSRIs) for autism spectrum disorders (ASD). Cochrane Database Syst Rev 2010;(8): CD004677.

14. Mamo D, Graff A, Mizrahi R, Shammi CM, Romeyer F, Kapur S. Differential effects of aripiprazole on D(2), 5-HT(2), and 5-HT(1A) receptor occupancy in patients with schizophrenia: a triple tracer PET study. Am J Psychiatry 2007; 164:1411-1417.

15. Stigler KA, Diener JT, Kohn AE, Li L, Erickson CA, Posey $\mathrm{DJ}$, et al. Aripiprazole in pervasive developmental disorder not otherwise specified and asperger's disorder: a 14-Week, prospective, open-label study. J Child Adolesc Psychopharmacol 2009;19:265-274. 